\title{
Association between Apolipoprotein B mRNA-editing Enzyme Catalytic Polypeptide-Like 3B (APOBEC3B) Deletion with HIV-1 Acquisition and AIDS among North Indian Population
}

\section{Kavita Kakkar ${ }^{1,2}$, Swati Sharma ${ }^{1,2}$, Anurag Rathore ${ }^{1}$, Satyendra K Singh ${ }^{1}$, Nikky Nyari $^{1}$, Manoj Km Singh ${ }^{3}$, Tapan N Dhole ${ }^{1 *}$, Vikas Agarwal ${ }^{4}$, Sayali Mukherjee ${ }^{2}$ and Naveen KM Srivastava ${ }^{1}$}

${ }^{1}$ Department of Microbiology Sanjay Gandhi Postgraduate Institute of Medical Sciences, Lucknow, India

${ }^{2}$ Amity Institute of Biotechnology, Amity University, Lucknow, India

${ }^{3}$ National University of Science and Technology, MISiS, Moscow

${ }^{4}$ Department of Immunology, Sanjay Gandhi Postgraduate Institute of Medical Sciences, Lucknow, India

\begin{abstract}
Objective: Apolipoprotein B mRNA-editing enzyme catalytic polypeptide-Like 3B (APOBEC3B) is involved in innate immune response, exhibiting insertion-deletion polymorphism across the world in human population. A naturally occurring $29.5 \mathrm{~kb}$ deletion removes complete APOBEC3B gene. Human APOBEC3B family of proteins restricts HIV1 replication. Very few studies have been conducted on this subject and the deductions regarding the effects of APOBEC3B deletion on HIV-1 susceptibility and pathogenesis have been largely inconsistent. Therefore, we studied the association of APOBEC3B deletion with HIV-1 in the North Indian population.
\end{abstract}

Methods: Insertion (I)/Deletion (D) APOBEC3B polymorphism was analyzed using Polymerase chain reaction. Infection rates as wells as stages of HIV were compared among the three genotypes: deletion-homozygous (D/D), Insertionhomozygous (I/I) and hemizygous (I/D) in 150 HIV-1 seropositive (HSP) and 250 HIV-1 seronegative (HSN) subjects.

Results and discussion: The genotypic analysis revealed insignificant associations among homozygous deletion ( $D / D)$ genotype $(P=0.130, O R=1.93,95 \% \mathrm{Cl}=0.95-4.30)$ and moderate associations among hemizygous (I/D) genotypes $(\mathrm{P}=0.057, \mathrm{OR}=1.56,95 \% \mathrm{Cl}-1.03-2.44)$ with $\mathrm{HIV}-1$ susceptibility and also the single copy of variant allele was more susceptible to HIV-1 infection. The severity of HIV-1 infection on the basis of CD4 count was not associated significantly with the disease progression to AIDS.

Conclusion: In conclusion, we found that the deletion genotype of APOBEC3B gene polymorphism does not play any significant role on HIV-1 susceptibility. Hence, further studies with the expansion of sample size are needed to validate the results.

Keywords: AIDS; Apolipoprotein; Cytidine deaminase; HIV; Disease susceptibility

\section{Introduction}

Human immunodeficiency virus (HIV) is the cause of Acquired Immuno Deficiency Syndrome (AIDS) infection, that targets the immune system guiding to a state of immunodeficiency in setting of immune activation, and the course of the disease is deeply influenced by inter-individual variability [1]. The acute phase of HIV infection is characterized by a substantial drop in CD4+ T cell count $[2,3]$.

The APOBEC (Apolipoprotein B mRNA-editing enzyme-catalytic polypeptide) serves as a shield to retro elements [4] belonging to cytidine deaminases family [5], comprising of seven host restriction factors (APOBEC3A-H) and has the ability to edit DNA/RNA which constitute an innate barrier to retroviruses, endogenous retro-elements and DNA viruses [6-8] and thus functions as DNA mutators, thereby, forming an important part of immune system, acting in both adaptive and innate immunity [9]. These cytidine deaminases object the genome of both the host and its invading pathogens [10]. APOBEC3 genes are located on chromosome 22 [11] and these proteins acts upon viral nucleic acids as a form of intrinsic host defense [12].

A3 (APOBEC3) enzymes are capable of editing single-stranded DNA and recognize specific target sequences [13-16]. It plays an important role in the innate immune system and acts upon host defense against exogenous viruses and endogenous retro elements [17-20].

For HIV-1 to successfully infect humans, it must overcome numerous physical and immunological barriers [21,22]. Within cells,
HIV must overcome a network of restriction factors that are able to block specific replication steps of the virus, including A3 Enzymes [23].

Viral infectivity factor (Vif) plays a role in HIV-1 to overcome A3 enzymes [13,23-26]. By disrupting the Vif-host cell interactions through novel pharmaceuticals, A3 enzymes can be used to suppress HIV-1 infection. APOBEC3B is resistant to Vif-mediated degradation [16] and is able to suppress the infectivity of both Vif-deficient and wild-type HIV-1 with equal efficiency [27]. These in vitro evidences suggest APOBEC3B as a potential strong inhibitor of HIV-1 in vivo. A segment spanning $29.5 \mathrm{~kb}$ between the fifth exon of APOBEC3A and eighth exon of APOBEC3B in chromosome 22 is deleted, which is frequently present among Asians [11].

Previous studies shows that the rate of progression of the disease

*Corresponding author: Dr. Tapan N Dhole, MD, Department of Microbiology, Sanjay Gandhi Postgraduate Institute of Medical Sciences, Lucknow-226014, India; Tel: +91-522-2494263; Fax: +91-522-2668100; +91-522-2668017; E-mail: tndhole@gmail.com

Received November 15, 2016; Accepted January 06, 2017; Published January 13, 2017

Citation: Kakkar K, Sharma S, Rathore A, Singh SK, Nyari N, et al. (2017)Association between Apolipoprotein B mRNA-editing Enzyme Catalytic Polypeptide-Like 3B (APOBEC3B) Deletion with HIV-1 Acquisition and AIDS among North Indian Population. J AIDS Clin Res 8: 653. doi: 10.4172/2155-6113.1000653

Copyright: ( 2017 Kakkar K, et al. This is an open-access article distributed unde the terms of the Creative Commons Attribution License, which permits unrestricted use, distribution, and reproduction in any medium, provided the original author and source are credited. 
Citation: Kakkar K, Sharma S, Rathore A, Singh SK, Nyari N, et al. (2017) Association between Apolipoprotein B mRNA-editing Enzyme Catalytic Polypeptide-Like 3B (APOBEC3B) Deletion with HIV-1 Acquisition and AIDS among North Indian Population. J AIDS Clin Res 8: 653. doi: 10.4172/2155-6113.1000653

Page 2 of 5

varies in HIV-1 infected individuals and several SNPs are responsible for it at different clinical stages of HIV-1/AIDS [28]. The mutation frequency of HIV-1/AIDS varies significantly depending upon the global, ethnic regional variations, giving each different population and region a different susceptibility profile pattern to HIV-1 infection and disease progression. Therefore, in the present study, we tried to find the association between APOBEC3B variants genes and the susceptibility to the HIV-1 infection.

\section{Materials and Methods}

\section{Study design and study subjects}

The study consists of $150 \mathrm{HIV}-1$ seropositive patients (HSP), enrolled from the outpatients attending the clinics of Sanjay Gandhi Post Graduate Institute of Medical Sciences, Lucknow India, during 2013-2014. Written information consent was taken through a questionnaire from the patient regarding the clinical information and their residing areas. Therefore, according to the questionnaire, only those who belong to North Indian ethnicity were included in the present study. The HIV-1 seropositive subjects were in different stages of disease progression and had no history or a less than 6 week prior history of antiretroviral therapy. HIV-1 seropositive patients (HSP) were divided into three subgroups as per the criteria of the Center for Disease Control and Prevention (CDC) based on CD4+ T-cell counts, clinical symptoms and disease severity $[29,30]$. The three groups were as follows: Stage I ( $\mathrm{n}=48$; asymptomatic HIV-1 patients in category A1 to A3), Stage II ( $n=72$ symptomatic HIV-1 patients without AIDS, category B1 to B3) and Stage III $(n=30$; symptomatic HIV-1 patients with AIDS). Only individuals who had a minimum follow-up time of at least 6 months were included in the study. The control population (HIV-1 seronegative, HSN) was a group of healthy volunteers with HIV-1 seronegative status coming to the blood bank of SGPGIMS, Lucknow. They all belong to the same ethnicity, age and gender. The mean age of $150 \mathrm{HSP}$ subjects was $34.17 \pm 13.23$ years and mean 440.02 \pm 407.9 CD4+ count with male to female ratio $14: 11$ and that of 250 HIV-1 seronegative (HSN) was $30.72 \pm 8.38$ years with male to female ratio 76:49. After receiving the information consent from HSP and HSN, $5 \mathrm{ml}$ whole blood was collected to evaluate the APOBEC3B gene deletion polymorphism. This study was approved by the Institutional Ethics Committee, SGPGIMS, Lucknow.

\section{Determination of HIV-1 status and CD4+ cell count}

All individuals were primarily screened for their HIV-1 status by primary screening, through ELISA (Vironostika, HIV Uni-FormII $\mathrm{Ag} / \mathrm{Ab}$, Biomerieux, Netherlands) and subsequently confirmed with Western Blot (LAV Blot I, BioRad, France). CD4 T-cell counts were measured by flow cytometer FAC Scan (Becton Dickinson Immunocytometry systems, San Jose, CA, USA) using fresh EDTAtreated whole blood at the time of recruitment.

\section{Genotyping of APOBEC3B (A3B) polymorphism}

The genomic DNA was extracted from $0.2-0.3 \mathrm{ml}$ peripheral blood leukocytes pellet using the standard salting out method [31]. In the present study, polymerase chain reaction (PCR) was performed to amplify Insertion (I) and deletion (D) regions of the APOBE3B gene, using genomic DNA extracted from HIV-1 infected patients and seronegative subjects. Genotyping for the APOBEC3B variants was carried out using polymerase chain reaction (PCR) followed by gel electrophoresis analysis. The primer sequences for APOBEC3B (A3B) were: A3B (Deletion) sense 5'-TAGGTGCCACCCCGAT-3' and antisense $5^{\prime}$ - TTGAGCATAATCTTACTCTTGTAC $-3^{\prime}$ and A3B
(Insertion) sense 5'- TTGGTGCTGCCCCCTC -3 and antisense $5^{\prime}$-TAGAGACTGAGGCC-CAT-3' [32,33]. Finally, the Insertion and Deletion reactions were performed separately in $20 \mu \mathrm{l}$ volume containing $10 \mu \mathrm{l} 2 \mathrm{X}$ PCR master mix (Fermentas, Vilnius, Lithuania), $0.1 \mathrm{mM}$ of each primer and $100 \mathrm{ng}$ of extracted DNA. DNA was amplified for initial denaturation at $95^{\circ} \mathrm{C}$ for $3 \mathrm{~min}$, followed by 35 cycles of $95^{\circ} \mathrm{C}$ for $30 \mathrm{~s} 56^{\circ} \mathrm{C}$ for $40 \mathrm{~s}$ and $72^{\circ} \mathrm{C}$ for $35 \mathrm{~s}$ and final extension at $72^{\circ} \mathrm{C}$ for $5 \mathrm{~min}$. The amplified products were subjected to $2 \%$ agarose gel electrophoresis at $80 \mathrm{~V}$ stained with ethidium bromide. The $700 \mathrm{bp}$ corresponds to Insertion (I) and $490 \mathrm{bp}$ to Deletion (D).

\section{Statistical analysis}

Statistical analysis was done by SPSS software version 11.5 (SPSS, Chicago, IL, U.S.A). The distribution of genotypic and allelic frequencies between case and control was measured using $\chi^{2}$ test or Fisher's exact test. Odds ratios (OR) and its $95 \%$ confidence interval (C.I.) were calculated to assess the risk conferred by a particular allele and genotype. Observed and expected genotype frequencies were compared by $\chi^{2}$ test to check deviation from Hardy Weinberg Equilibrium. $P$ value $\leq 0.05$ was considered to be statistically significant. The sample size was calculated using the QUANTO ver. 1 program (http://hydra.use.edu/gxe).

\section{Results and Discussion}

\section{Demographic characteristics of HSP patients and HSN control subjects}

To determine the frequency of Insertion (I) and deletion (D) alleles of APOBEC3B in North Indian population, we studied 150 HSP patients which included 84 (56\%) males and 66 (44\%) females. The HSN group consisted of 250 healthy individuals, including $152(60.8 \%)$ male and 98 (39.2\%) female subjects. The mean \pm SD values for CD4 count of the three stages were (Stage I=777.69 \pm 564.1 , Stage II $=351.76$ \pm 81.67 , Stage III $=112.3 \pm 58.61$ ). The demographic characteristics of the studied subjects are mentioned in Table 1.

\begin{tabular}{|c|c|c|c|}
\hline Characteristics & Mean \pm SD & P-value & $\begin{array}{c}\text { Male/Female } \\
\text { Ratio }\end{array}$ \\
\hline \multicolumn{4}{|c|}{ HIV-1 seronegative (HSN; $n=250$ ) } \\
\hline Age & $30.72 \pm 8.38$ & Ref & $76: 49$ \\
\hline \multicolumn{4}{|l|}{ Sex (M/F ratio) } \\
\hline CD4 counts/ $\mu \mathrm{l}$ & $N D^{*}$ & & \\
\hline \multicolumn{4}{|c|}{ HIV-1 seropositive (HSP; $n=150$ ) } \\
\hline Age & $34.17 \pm 13.23$ & 0.347 & \\
\hline Sex (M/F ratio) & & & $14: 11$ \\
\hline 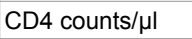 & $440.02 \pm 407.9$ & & \\
\hline \multicolumn{4}{|l|}{ Stage I $(n=48)$} \\
\hline Age & $31.29 \pm 14.10$ & & \\
\hline Sex (M/F ratio) & & 0.485 & $1 / 1$ \\
\hline 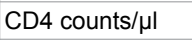 & $777.69 \pm 564.13$ & $<0.0001$ & \\
\hline \multicolumn{4}{|l|}{ Stage II (n=72) } \\
\hline Age & $35.13 \pm 13.72$ & & \\
\hline Sex (M/F ratio) & & 1.00 & $1 / 1$ \\
\hline 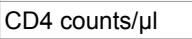 & $351.76 \pm 81.67$ & $<0.0001$ & \\
\hline \multicolumn{4}{|l|}{ Stage III $(n=30)$} \\
\hline Age & $36.5 \pm 9.74$ & & \\
\hline Sex (M/F ratio) & & & $2 / 3$ \\
\hline CD4 counts/ $\mu \mathrm{l}$ & $112.3 \pm 58.61$ & Ref & \\
\hline
\end{tabular}

Unpaired t-test was applied to compare the mean of multiple variables in HSP and $\mathrm{HSN}$, and $\mathrm{P} \leq 0.05$

*ND: Not Detected

Table 1: Demographic and clinical characteristics of the HIV-1 seropositive (HSP) and HIV-1 seronegative (HSN) individuals. 
Citation: Kakkar K, Sharma S, Rathore A, Singh SK, Nyari N, et al. (2017) Association between Apolipoprotein B mRNA-editing Enzyme Catalytic Polypeptide-Like 3B (APOBEC3B) Deletion with HIV-1 Acquisition and AIDS among North Indian Population. J AIDS Clin Res 8: 653 . doi: 10.4172/2155-6113.1000653

Page 3 of 5

\section{Association of APOBEC3B insertion/deletion polymorphism and disease susceptibility with HSP (HIV-1 seropositive) and HSN (HIV-1 seronegative) subjects}

The observed and expected frequencies for the homozygous wild, heterozygous and homozygous variants did not deviate and were consistent with HWE in HIV-1 cases (HSP) and control subjects (HSN) (For HSP ${ }_{\text {HWE }} \mathrm{P}=0.053$; $\mathrm{HSN}_{\mathrm{HWE}} \mathrm{P}=0.079$ ). The gel pattern of A3B Ins/Del genotypes has been depicted in Figure 1. For APOBEC3B hemizygous Ins/Del genotype was $27.3 \%$ in HSP and $35.2 \%$ in HSN and a single copy of variant D allele was $19.7 \%$ in HSP and $27.2 \%$ in HSN. The logistic regression analysis revealed that on comparison of HSP with HSN (control) subjects, the data reveals that the hemizygous Ins/ Del genotype was associated with a moderate risk of HIV-1 infection with a borderline statistical significance $(\mathrm{P}=0.057, \mathrm{OR}=1.56)$ in comparison with homozygous Ins/Ins genotype. However, homozygous variant Del/Del genotype of HSP subjects was not associated with the disease susceptibility $(\mathrm{P}=0.130)$ when compared with HSN subjects. Similarly, individuals who have at least a single copy of variant $\mathrm{D}$ allele were more susceptible to HIV-1 infection on comparing HSP with HSN (control) subjects $(\mathrm{P}=0.017, \mathrm{OR}=1.53,95 \% \mathrm{CI}=1.08-2.16)$ (Table 2). Furthermore, on comparing HSP with HSN subjects it was illustrated that the dominant model (I/I vs. I/D+D/D) increased the risk of HIV1 infection $\left(\mathrm{P}_{\text {dominant }}=0.027, \mathrm{OR}=1.62,95 \% \mathrm{CI}=1.07-2.47\right)$ respectively.

\section{Association between APOBEC3B genotypes with disease} severity and progression to death on the basis of $\mathrm{CD} 4$ count

To evaluate the influence of APOBEC3B genotypes/alleles with disease progression, analysis was performed among HSP individuals classified into Stage I $(n=48)$, Stage II $(n=72)$, Stage III $(n=30)$ on the basis of disease severity and CD4+ T-cell count. Frequency of hemizygous I/D genotype was almost similar in all the three stages: Stage I, Stage II and Stage III and also the genotype was not significantly associated with the risk of disease progression, when Stage I and II was compared with Stage III as depicted in Table 3. Similarly, the frequency of homozygous variant D/D genotype was almost similar in Stage I and Stage II as compared to Stage III with no statistical difference (Pstage $_{\mathrm{I}}=0.299, \mathrm{OR}=3.10,95 \% \mathrm{CI}=0.61-15.91$ and Pstage $_{\mathrm{II}}=0.719$, $\mathrm{OR}=1.92,95 \% \mathrm{CI}=0.38-9.67)$. Also, the frequency of single copy of

\begin{tabular}{|l|c|c|c|c|c|}
\hline Genotype & $\begin{array}{c}\text { HSP } \\
\text { (n=150) (\%) }\end{array}$ & $\begin{array}{c}\text { HSN } \\
(\mathbf{n = 2 5 0 )} \text { (\%) }\end{array}$ & P-value & OR & 95\% CI \\
\hline A3B Ins/Del & & & & & \\
\hline Ins/Ins (I/I) & $100(66.7)$ & $138(55.2)$ & Ref & & \\
\hline Ins/Del (I/D) & $41(27.3)$ & $88(35.2)$ & 0.057 & 1.56 & $1.03-2.44$ \\
\hline Del/Del (D/D) & $9(6.0)$ & $24(9.6)$ & 0.130 & 1.93 & $0.95-4.30$ \\
\hline I & $241(80.3)$ & $364(72.8)$ & Ref & & \\
\hline D & $59(19.7)$ & $136(27.2)$ & 0.017 & 1.53 & $1.08-2.16$ \\
\hline Dominant model & & & & & \\
\hline I/I vs. I/D+D/D & & & 0.027 & 1.62 & $1.07-2.47$ \\
\hline Recessive model & & & & & \\
\hline I/I+I/D vs. D/D & & & 0.260 & 1.67 & $0.78-3.68$ \\
\hline
\end{tabular}

P-value was determined by $\mathrm{X}^{2}$ test. OR: Odds Ratio; $\mathrm{Cl}$ : Confidence Interval Table 2: Association between APOBEC3B deletion polymorphism and HIV-1 susceptibility and progression among the studied subjects.
A

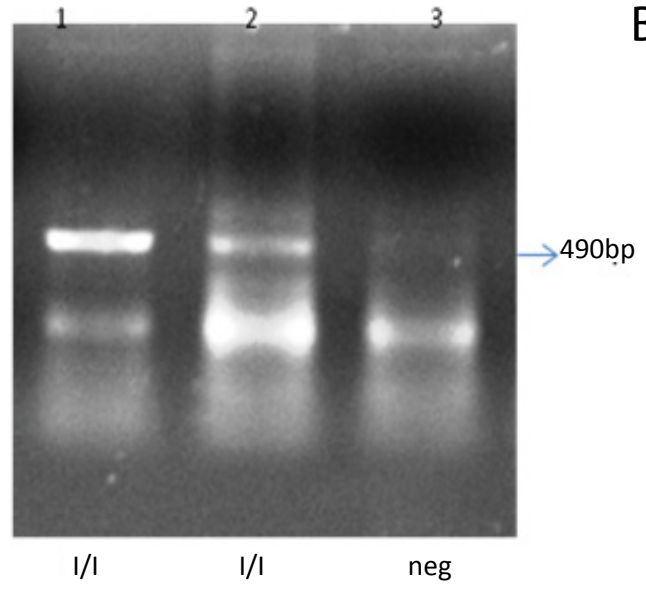

B

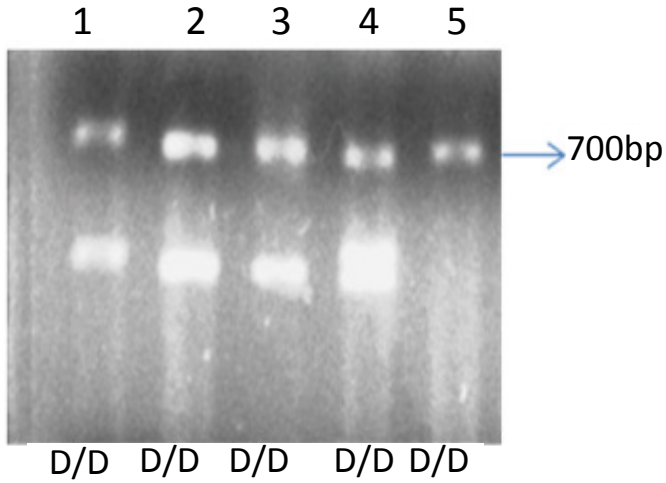

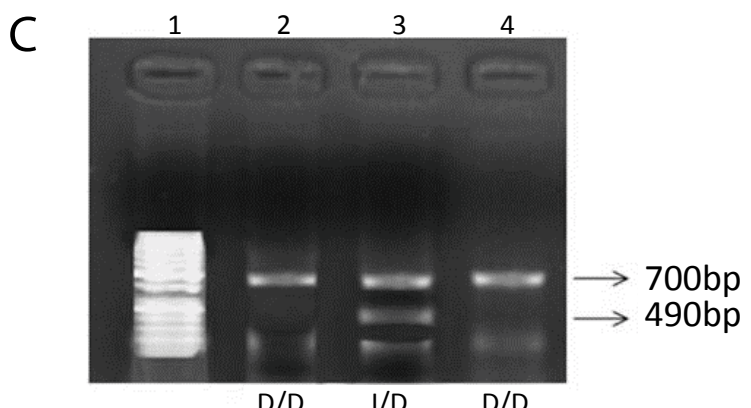

$D / D \quad I / D \quad D / D$

Figure 1: (a) Lane 1 and 2 - I/l; lane 3 - negative; 1 (b) Lane 1-5 - D/D; 1 (c) Lane 1 - marker; lane 2 and 4 - D/D; lane 3 - I/D. 
Citation: Kakkar K, Sharma S, Rathore A, Singh SK, Nyari N, et al. (2017) Association between Apolipoprotein B mRNA-editing Enzyme Catalytic Polypeptide-Like 3B (APOBEC3B) Deletion with HIV-1 Acquisition and AIDS among North Indian Population. J AIDS Clin Res 8: 653. doi: 10.4172/2155-6113.1000653

Page 4 of 5

\begin{tabular}{|c|c|c|c|c|c|c|c|c|c|}
\hline \multirow[t]{2}{*}{ Genotype } & \multirow{2}{*}{$\begin{array}{l}\text { Stage I } \\
(n=48)\end{array}$} & \multirow{2}{*}{$\begin{array}{l}\text { Stage II } \\
(n=72)\end{array}$} & \multirow{2}{*}{$\begin{array}{l}\text { Stage III } \\
(n=30)\end{array}$} & \multicolumn{3}{|c|}{ Stage III vs. Stage I } & \multicolumn{3}{|c|}{ Stage III vs. Stage I } \\
\hline & & & & $P$ value & OR & C.I (95\%) & $P$ value & OR & C.I (95\%) \\
\hline \multicolumn{10}{|c|}{ APOBEC3B Ins/Del } \\
\hline $\mathrm{I} / \mathrm{I}$ & $29(60.4)$ & $47(65.3)$ & $20(66.7)$ & \multicolumn{3}{|c|}{ Reference } & \multicolumn{3}{|c|}{ Reference } \\
\hline I/D & $10(20.8)$ & $16(22.2)$ & $8(26.7)$ & 0.788 & 0.86 & $(0.29-2.57)$ & 0.799 & 0.85 & $(0.31-2.31)$ \\
\hline D/D & $9(18.8)$ & $9(12.5)$ & $2(6.6)$ & 0.299 & 3.10 & $(0.61-15.91)$ & 0.719 & 1.92 & $(0.38-9.67)$ \\
\hline I & $68(70.8)$ & $110(76.4)$ & $48(80.0)$ & \multicolumn{3}{|c|}{ Reference } & \multicolumn{3}{|c|}{ Reference } \\
\hline D & $28(29.2)$ & $34(23.6)$ & $12(20.0)$ & 0.259 & 1.65 & $(0.76-3.56)$ & 0.713 & 1.24 & $(0.59-2.59)$ \\
\hline
\end{tabular}

Table 3: Distribution of A3B Gene/alleles among HIV seropositive North Indian individuals classified on the basis of severity of the disease and progression to AIDS.

variant D allele was similar in Stage I and Stage II when compared to Stage III and was not associated with the HIV-1 disease progression (Table 3).

\section{Conclusion}

The APOBEC3B deletion, which results in the loss of at least one copy of the unique coding portion of APOBEC3B, ranges in frequency from 0 to $43 \%$ in Indian populations with the lowest deletion frequency seen in populations inhabiting in malaria endemic regions of India [32]. This is the only human APOBEC3 protein with intrinsic anti-HIV-1 activity that is resistant to HIV-1 Vif $[16,20,27,34]$. Recent studies have indicated that APOBEC3B mRNA expression is inactivated in CD4+ T-cells and lymphoid cells $[20,35]$. The consistency of the associations between the null genotype (D/D) and acquisition of HIV-1 infection, progression to AIDS, supports an active role for APOBEC3B against HIV-1 in vivo [33].

In this population based case-control study, we investigated the influence of APOBEC3B gene polymorphism on HIV-1 susceptibility in a North Indian population. Our finding suggests that the APOBEC3B gene polymorphism was moderately associated with susceptibility to HIV-1 infection. However, the low incidence of deletion allele in certain populations around the world is because of insignificant association of APOBEC3B deletion polymorphism [11].

Also, as depicted from the present study, the frequency distribution of APOBEC3B genotypes was fairly similar in Stage I and Stage II as compared with Stage III and there was no statistical significant difference in the distribution of APOBEC3B genotypes in Stage I and Stage II when compared with Stage III.

The APOBEC3 gene family encodes cytosine deaminases which have been implicated in innate cellular immunity by restricting retroviruses, mobile genetic elements like retro-transposons and endogenous retroviruses [24,36]. Furthermore, the APOBEC3 genes may play a role in carcinogenesis by triggering DNA mutation through $\mathrm{dC}$ deamination [37]. Moreover, expression of the APOBEC3 genes is regulated by estrogen [38], a hormone that plays a central role in the etiology of breast cancer. APOBEC3B genes are induced during the acute stage of HIV-1 infection but returns to baseline levels in the asymptomatic stage [35]. APOBEC3 gene family encodes proteins that exhibits intracellular defense against viral infection [39].

However, in a study by Rezaei on Southeast Iranian population, showing that $\mathrm{I} / \mathrm{D}$ as well as $\mathrm{I} / \mathrm{D}+\mathrm{D} / \mathrm{D}$ genotype increased the risk of $\mathrm{BC}$ in comparison with I/I genotype, thus suggesting that the APOBEC3 deletion polymorphism increased the risk of Breast Cancer in Iranian population which is similar to the results of the present study [40].

Also, a study by Jha et al. depicts a strong association of deletion allele with susceptibility to falciparum malaria in endemic regions [32], which was in corroboration with our study.
Similarly, early reports suggests that genome-wide association study performed by Long et al. on Chinese population depicts a strong association between common deletion in the APOBEC 3 gene and Breast cancer [41]. Their findings showed the ORs of $1.31(95 \%$ $\mathrm{CI}=1.21-1.42)$ for a one-copy deletion and 1.76 (95\% CI=1.57-1.97) for a two-copy deletion. The result was also replicated among women of European ancestry and the findings showed that the deletion was significantly associated with breast cancer risk, with ORs and 95\% CIs of 1.21 (1.02-1.43) for one copy deletion and 2.29 (1.04-5.06) for twocopy deletion in comparison with no deletion [42].

Also, in a study by Qi et al., they investigated the possible association between APOBEC3 gene deletion and risk of epithelial ovarian cancer (EOC) in Chinese population [43]. They found that one copy deletion as well as two-copy deletion of APOBEC3 significantly increased the risk of EOC in comparison with subjects with no deletions.

Similarly, in a study by Itaya et al., which revealed no association of deletion allele and homozygous genotype between non-progressors and slow progressors of HIV-1 infected subjects? Also, no effects of HIV viral load and CD4+ T-cell count characterizing different stages of the disease severity were seen in association with the APOBEC3B polymorphism was in corroboration with our results [44].

Our results were also similar with the study by Ping et al., which showed that there is no association of hemizygous (Ins/Del) genotype compared to reference I/I genotype on the progression of HIV-1 to AIDS/Death, when HSP subjects were compared to HSN (control) subjects [33].

The varied frequency of the APOBEC3B deletion shows considerable range and population stratification. However, study by Kidd et al. [11] reported that the clinical increase in deletion frequency in HGDP populations as one moves eastward from Africa, following the route of human migration. However, pairwise $\mathrm{F}_{\mathrm{ST}}$ (fixation index statistic) estimates in their study differentiated Amerindian, Oceanic and some East Asian populations from other populations based on the frequency of the deletion in comparison to other in del polymorphisms and SNPs. This indicated that the pattern of distribution of the APOBEC3B deletion is not the result of demographic history alone [45].

The present study has a few limitations. Firstly, our HIV-1 seropositive sample size was relatively small and therefore the study's statistical power may have been limited. Also, it may be important to continue our study with a larger sample size and with ethnic variations as it would be further helpful to investigate the role of APOBEC3B gene with the risk of the disease and also with other pathogens. In conclusion, we infer that the deletion polymorphism of APOBEC3B gene is not involved with the risk of HIV-1 disease susceptibility and AIDS among the North Indian population. But still further studies for the expansion of this study is needed to validate the results and also designing therapeutics aimed at APOBEC3-Vif axis. 
Citation: Kakkar K, Sharma S, Rathore A, Singh SK, Nyari N, et al. (2017) Association between Apolipoprotein B mRNA-editing Enzyme Catalytic Polypeptide-Like 3B (APOBEC3B) Deletion with HIV-1 Acquisition and AIDS among North Indian Population. J AIDS Clin Res 8: 653. doi: $10.4172 / 2155-6113.1000653$

Page 5 of 5

\section{Acknowledgement}

This project was supported by the Senior Research Fellowship awarded to Ms. Kavita Kakkar (File no.- 80/721/2012/ECD-1) and Swati Sharma (file no80/804/2013/ECD-1) by Indian Council of Medical Research, ICMR, New Delhi.

\section{References}

1. Kaur G, Mehra N (2009) Genetic determinants of HIV-1 infection and progression to AIDS: susceptibility to HIV infection. Tissue Antigens 73: 289 301

2. Li Q1, Duan L, Estes JD, Ma ZM, Rourke T, et al. (2005) Peak SIV replication in resting memory CD4+ T cells depletes gut lamina propria CD4+ T cells. Nature 434: 1148-1152.

3. Mattapallil JJ, Douek DC, Hill B, Nishimura Y, Martin M, et al. (2005) Massive infection and loss of memory CD4+ T cells in multiple tissues during acute SIV infection. Nature 434: 1093-1097.

4. MacDuff DA, Demorest ZL, Harris RS (2009) AID can restrict L1 retrotransposition suggesting a dual role in innate and adaptive immunity. Nucleic Acids Res 37: 1854-1867.

5. Conticello SG, Langlois MA, Yang Z, Neuberger MS (2007) DNA deamination in immunity: AID in the context of its APOBEC relatives. Adv Immunol 94: 37-73.

6. Chiu YL, Greene WC (2008) The APOBEC3 cytidine deaminases: An innate defensive network opposing exogenous retroviruses and endogenous retroelements. Annu Rev Immunol 26: 317-353.

7. Holmes RK, Malim MH, Bishop KN (2007) APOBEC-mediated viral restriction: Not simply editing? Trends Biochem Sci 32: 118-128.

8. LaRue RS, Andrésdóttir V, Blanchard Y, Conticello SG, Derse D, et al. (2009) Guidelines for naming nonprimate APOBEC3 genes and proteins. J Virol 83: 494-497.

9. Hamilton CE, Papavasiliou FN, Rosenberg BR (2010) Diverse functions for DNA and RNA editing in the immune system. RNA Biol 7: 220-228.

10. Narvaiza I, Landry S, Weitzman MD (2012) APOBEC3 proteins and genomic stability: The high cost of a good defence. Cell Cycle 11: 33-38.

11. Kidd JM, Newman TL, Tuzun E, Kaul R, Eichler EE (2007) Population stratification of a common APOBEC gene deletion polymorphism. PLoS Genet 3: e63.

12. Rosenberg BR, Papavasiliou FN (2007) Beyond SHM and CSR: AID and related cytidine deaminases in the host response to viral infection. Adv Immunol 94: $215-244$

13. Harris RS, Bishop KN, Sheehy AM, Craig HM, Petersen-Mahrt SK, et al. (2003) DNA deamination mediates innate immunity to retroviral infection. Cell 113: 803-809.

14. Beale RC, Petersen-Mahrt SK, Watt IN, Harris RS, Rada C, et al. (2004) Comparison of the differential context-dependence of DNA deamination by APOBEC enzymes: correlation with mutation spectra in vivo. J Mol Biol 337: 585-596.

15. Armitage AE, Katzourakis A, de Oliveira T, Welch JJ, Belshaw R, et al (2008) Conserved footprints of APOBEC3G on Hypermutated human immunodeficiency virus type 1 and human endogenous retrovirus HERVK(HML2) sequences. J Virol 82: 8743-8761.

16. Bishop KN, Holmes RK, Sheehy AM, Davidson NO, Cho SJ, et al. (2004) Cytidine deamination of retroviral DNA by diverse APOBEC proteins. Curr Biol 14: $1392-1396$

17. Bogerd HP, Wiegand HL, Doehle BP, Lueders KK, Cullen BR (2006)APOBEC3A and $A P O B E C 3 B$ are potent inhibitors of LTR-retrotransposon function in human cells. Nucleic Acids Res 34: 89-95.

18. Kinomoto M, Kanno T, Shimura M, Ishizaka Y, Kojima A, et al. (2007). Al APOBEC3 family proteins differentially inhibit LINE-1 retrotransposition. Nucleic Acids Res 35: 2955-2964.

19. Delebecque F, Suspène R, Calattini S, Casartelli N, Saïb A, et al. (2006) Restriction of foamy viruses by APOBEC cytidine deaminases. J Virol 80: 605-614

20. Yu Q, Chen D, König R, Mariani R, Unutmaz D, et al. (2004) APOBEC3B and APOBEC $3 C$ are potent inhibitors of simian immunodeficiency virus replication. J Biol Chem 279: 53379-53386.

21. Shaw GM, Hunter E (2012) HIV transmission. Cold Spring Harb Perspect Med 2.
22. Ma J, Li X, Xu J, Zhang Q, Liu Z, et al. (2013) The roles of APOBEC3G complexes in the incorporation of APOBEC3G into HIV-1. PLoS One 8: e74892.

23. Sheehy AM, Gaddis NC, Choi JD, Malim MH (2002) Isolation of a human gene that inhibits HIV-1 infection and is suppressed by the viral Vif protein. Nature 418: 646-650.

24. Conticello SG, Harris RS, Neuberger MS (2003) The Vif protein of HIV triggers degradation of the human antiretroviral DNA deaminase APOBEC3G. Curr Biol 13: $2009-2013$.

25. Mangeat B1, Turelli P, Caron G, Friedli M, Perrin L, et al. (2003) Broad antiretroviral defence by human APOBEC3G through lethal editing of nascent reverse transcripts. Nature 424: 99-103.

26. Mariani R, Chen D, Schröfelbauer B, Navarro F, König R, et al. (2003) Species specific exclusion of APOBEC3G from HIV-1 virions by Vif. Cell 114: 21-31.

27. Doehle BP, Schäfer A, Cullen BR (2005) Human APOBEC3B is a potent inhibitor of HIV-1 infectivity and is resistant to HIV-1 Vif. Virology 339: 281-288.

28. Lama J, Planelles $V$ (2007) Host factors influencing susceptibility to HIV infection and AIDS progression. Retrovirology 4: 52.

29. Vajpayee M, Kanswal S, Seth P, Wig N (2003) Spectrum of opportunistic infections and profile of CD4+ counts among AIDS patients in North India. Infection 31: 336-340.

30. McNicholl JM, Lal RB, Kaslow R (2003) Human immunodeficiency virus (HIV) infection. Encyclopedia of the Human Genome. Nature Publishing Group, New York.

31. Miller SA, Dykes DD, Polesky HF (1988) A simple salting out procedure for extracting DNA from human nucleated cells. Nucleic Acids Res 16: 1215.

32. Jha P1, Sinha S, Kanchan K, Qidwai T, Narang A, et al. (2012) Deletion of the APOBEC3B gene strongly impacts susceptibility to falciparum malaria. Infect Genet Evol 12: 142-148.

33. An P, Johnson R, Phair J, Kirk GD, Yu XF, et al. (2009) APOBEC3B deletion and risk of HIV-1 acquisition. J Infect Dis 200: 1054-1058.

34. Romani B, Engelbrecht S, Glashoff RH (2009) Antiviral roles of APOBEC proteins against HIV-1 and suppression by Vif. Arch Virol 154: 1579-1588.

35. Li Q, Smith AJ, Schacker TW, Carlis JV, Duan L, et al. (2009) Microarray analysis of lymphatic tissue reveals stage-specific, gene expression signatures in HIV-1 infection. J Immunol 183: 1975-1982.

36. Conticello SG (2008) The AID/APOBEC family of nucleic acid mutators. Genome Biol 9: 229

37. Suspène R, Aynaud MM, Guétard D, Henry M, Eckhoff G, et al. (2011) Somatic hypermutation of human mitochondrial and nuclear DNA by APOBEC3 cytidine deaminases, a pathway for DNA catabolism. Proc Natl Acad Sci USA 108 4858-4863.

38. Komatsu A, Nagasaki K, Fujimori M, Amano J, Miki Y (2008) Identification of novel deletion polymorphisms in breast cancer. Int J Oncol 33: 261-270.

39. Eichler EE, Flint J, Gibson G, Kong A, Leal SM, et al. (2010) Missing heritability and strategies for finding the underlying causes of complex disease. Nat Rev Genet 11: 446-450.

40. Rezaei M, Hashemi M, Hashemi SM, Mashhadi MA, Taheri M (2015) APOBEC3 Deletion is Associated with Breast Cancer Risk in a Sample of Southeast Iranian Population. IJMCM 4: 103-108.

41. Long J, Delahanty RJ, Li G, Gao YT, Lu W, et al. (2013) A common deletion in the APOBEC3 genes and breast cancer risk. J Natl Cancer Inst 105: 573-579.

42. Xuan D, Li G, Cai Q, Deming HS, Shrubsole MJ, et al. (2013) APOBEC3 deletion polymorphism is associated with breast cancer risk among women of European ancestry. Carcinogenesis 34: 2240-2243.

43. Qi G, Xiong H, Zhou C (2014) APOBEC3 deletion polymorphism is associated with epithelial ovarian cancer risk among Chinese women. Tumour Biol 35: 5723-5726.

44. Itaya S, Nakajima T, Kaur G, Terunuma H, Ohtani H, et al. (2010) No evidence of an association between the APOBEC3B deletion polymorphism and susceptibility to HIV infection and AIDS in Japanese and Indian populations. J Infect Dis 202: 815-816.

45. Kidd JM, Newman TL, Tuzun E, Kaul R, Eichler EE (2007) Population stratification of a common APOBEC gene deletion polymorphism. PLoS Genet 3: e63. 